\title{
Pollen Ontogeny Comparison of Natural Male-Fertile Diploid and Male-Sterile Triploid Lilium lancifolium in Korea
}

\author{
Gyeong Ran Do \\ Fruit Division, National Institute of Horticultural and Herbal Science, Rural Development Administration, \\ Nongsaengmyeong-ro, 100, Jeonju, Republic of Korea; and Environmental Horticulture, University of \\ Seoul, Seoulsiripdaro 163, Seoul, Republic of Korea \\ Ju Hee Rhee ${ }^{1}$ \\ National Agrobiodiversity Center, National Academy of Agricultural Science, Rural Development \\ Administration, Nongsaengmyeong-ro, 370, Jeonju, Republic of Korea; and Bioversity International, \\ P.O. Box 236, UPM Post Office, Serdang, Selangor Darul Ehsan 43400, Malaysia \\ Wan Soon Kim \\ Environmental Horticulture, University of Seoul, Seoulsiripdaro 163, Seoul, Republic of Korea \\ Yun Im Kang \\ Floriculture Research Division, National Institute of Horticultural and Herbal Science, Rural \\ Development Administration, Nongsaengmyeong-ro 100, Jeonju, Republic of Korea
}

In Myung Choi, Jeom Hwa Han, Hyun Hee Han, Su Hyun Ryu, and Han Chan Lee

Fruit Division, National Institute of Horticultural and Herbal Science, Rural Development

Administration, Nongsaengmyeong-ro, 100, Jeonju, Republic of Korea

\begin{abstract}
AdDitional INDEX words. polyploidy, pollen development, fertility, abnormal tetrad
Abstract. Lilium lancifolium (syn. L. tigrinum) is the only polyploidy-complex species involving both diploid $(2 n=2 x=$ 24) and triploid $(2 n=3 x=36)$ plants in the genus. The origin of natural triploid remains a mystery and research has been limited mainly to chromosomal studies that have overlooked research on pollen ontogeny. By spatiotemporal comparison of the development and morphology of diploid and triploid pollen grains, we study the correlations between pollen fertility and morphological development in diploid and triploid plants and propose the necessity and importance of further research on natural polyploid-ontogenetic diversity. In this comparative investigation, we used various microscopy techniques including histological analyses, scanning electron microscopy (SEM), and transmission electron microscopy (TEM). The main morphological differences between triploid and diploid pollen grains started with abnormal tetrad formation of triploid, followed by inadequate amylogenesis and amylolysis in young microspores, and finished with the formation of an abnormal structure of pollen surface layers in maturing pollen grains, which finally resulted in pollen grain unfolding and male sterility. From observing the series of morphological events that induced male-sterile pathway in natural triploid pollens, this study showed a variety of correlations between pollen development and fertility, which differed from male sterility resulting from gene mutation, indicating that there exists greater variability in pollen male-sterile ontogeny. Our results suggest that multilateral research is required for understanding the fickle ontogeny of natural male-sterile polyploid.
\end{abstract}

The genus Lilium of the family Liliaceae comprises more than 100 species that are divided into seven sections. A great diversity of flower color, shape, fragrance, and other phenotypic and physiological characteristics is found in the wild species that are dispersed in the Northern Hemisphere, mainly in Asia, North America, and Europe (Hwang et al., 2011; Kim et al., 2005). Consequently, this genus occupies a prominent place in horticulture as cut flowers, and pot and garden plants. In this cosmopolitan plant genus, Lilium lancifolium (syn. L. tigrinum) is the only polyploidy-complex species in which diploid $(2 n=2 x=24)$ and triploid $(2 n=3 x=36)$ plants coexist naturally in the wild (Hwang et al., 2011; Kim et al., 2005; Noda, 1986).

Received for publication 19 May 2015. Accepted for publication 14 Aug. 2015. ${ }^{1}$ Corresponding author. E-mail: j.rhee@cgiar.org.
This special characteristic has attracted the interest of many researchers. The chromosome number of $L$. lancifolium was reported to be $2 n=24$ by Schaffner (1906) and, later, Takenaka and Nagamatsu (1930) first reported a triploid L. lancifolium. Since these reports, several investigations of the meiosis and mitosis processes in several forms of $L$. lancifolium have studied the natural polyploidy present in this species (De Jong, 1974; Hwang et al., 2011; Kim et al., 2006; Noda, 1978; Okazaki, 1994; Stewart and Bamford, 1943). In particular, selfsterility is a typical characteristic of triploid L. lancifolium (Chandler et al., 1937; Niizeki, 1961). This sterility has been attributed to an irregular distribution of chromosomes in the spore cell due to the lagged chromosomes resulting from the balancing effect of the cell toward a harmonized state of the nucleus to accept an irregular set of chromosomes or the lack of the moving activity from a physiological disorder in the 
spore mother cells (Niizeki, 1961; Takenaka and Nagamatsu, 1930). L. lancifolium was considered as autotriploid because the chromosome trios were structurally homologous (Chandler et al., 1937; Takenaka and Nagamatsu, 1930); however, it was later reported that all botanical varieties of L. lancifolium are allotriploid (Hwang et al., 2011; Stewart and Bamford, 1943). The chromosome number and complements of the diploid and triploid have been confirmed by several researchers. It was reported that four types of nucleolar chromosomes are common to nucleolar systems in mitoses of the diploid and triploid forms (Noda, 1978). Karyotypes of diploid and triploid L. lancifolium were analyzed and clarified using chromosome morphological data, fluorescence in situ hybridization karyotypes by using $5 \mathrm{~S}$ rDNA and 45S rDNA probes and 4',6-diamidino-2phenylindole band patterns (Hwang et al., 2011).

Despite the numerous studies, the origin of the triploid remains a mystery, with two competing hypotheses: either an allotriploid origin or an autotriploid origin. Noda (1986) suggested that the allotriploid was produced by natural interspecific hybridization between the diploid and a closely related diploid species, such as Lilium leichtlinii, or an autotriploid might be produced by crossing a functional unreduced gamete $(2 n)$ and abnormal reduced gamete $(n)$ between diploid individuals. Because of the limited geographic distribution of the diploid and the mystery of the triploid origin, the diploid presence is generally unrecognized and only the triploid being publically known (Kim et al., 2005).

Unfortunately, most of the numerous studies on L. lancifolium have focused only on the pairing and morphology of diploid and triploid chromosomes (De Jong, 1974; Hwang et al., 2011; Kim et al., 2006; Moens, 1969; Noda, 1978; Okazaki, 1994; Stewart and Bamford, 1943), with only a few studies investigating the difference in regional distribution and phenotype (Kim et al., $2005,2006)$. The gross morphology of the diploid form with numerous stem-bulbils closely resembles that of the triploid form (Kim et al., 2005; Noda, 1978). The fact that triploid plants have mostly sterile pollens is already widely known. So, little research has been conducted on the histological visualization and localization on triploid pollen morphological features or their developmental process after the irregular distribution of chromosomes at meiosis. There is no palynological investigation on the morphologically spatial and temporal occurrence of malesterile triploid pollen.

In this study, we compared the development and morphology of natural diploid pollen and triploid pollen in L. lancifolium. Our comparative results cannot entirely represent malesterile pollen physiology, but our research findings can contribute to the research on the ontogenetic characteristics of naturally occurring male-sterile triploid pollen as another branch of divergence of the pathways leading to male sterility. This article aimed to study the spatiotemporal correlations between pollen morphology (ontogenesis) and fertility in natural male-sterile triploid $L$. lancifolium to provide helpful information about the mechanism responsible for male-sterile pollen, and to propose the need for multilateral research on the fickle ontogeny of the natural male-sterile polyploid.

\section{Materials and Methods}

Plant material sampling. A diploid L. lancifolium of native origin was collected from Gungpyeong, Gyeonggi Province, on the west coast of Korea in 2009. A triploid accession was collected from the natural population at Inland Yeoju, Gyeonggi Province, Korea in the same year. Flower buds were sampled from plants grown in the greenhouses of the National Institute of Horticultural and Herbal Science, Rural Development Administration (RDA), Suwon, Korea, over a period of 4 years. We confirmed that the sampled diploid plant formed seed and the triploid did not. Ploidy level was detected with a flow cytometry (Ploidy Analyser-II; Partec, Görlitz, Germany) using nuclear samples prepared from chopped leaf with a sharp razor blade (Rhee et al., 2005). The pollen viability and germination tests were performed with the fluorochromatic reaction test based in fluorescein diacetate and in vitro pollen germination (Rhee et al., 2005). The results are shown in Table 1. To control the pollen development stage, we referred to Nakamura (1979) and Clément et al. (1996). Several flower buds from each plant and several stamens per bud were sampled from flower buds in different stages of development just before anthesis and classified according to anther length related to the pollen development stage during flowering season. To study the pollen morphology and size, dehisced anthers were prepared by the standard acetolysis method (Erdtman, 1960) and stored at $-70^{\circ} \mathrm{C}$ in deep freezer.

LIGHT MICROSCOPY AND TEM. The procedures were modified from a previously reported method (Clément et al., 1996). Anthers were fixed in $2.5 \%$ glutaraldehyde $(\mathrm{v} / \mathrm{v}$ in a $0.1 \mathrm{M}$ phosphate buffer) at $\mathrm{pH} 7.2$ in the presence of $4 \%$ sucrose $(\mathrm{w} / \mathrm{v})$ for $24 \mathrm{~h}$. After three rinses (15 min, each) with the above buffer, anthers were postfixed with $1 \% \mathrm{OsO} 4 \mathrm{w} / \mathrm{v}$ in the same buffer with $4 \%$ sucrose $(\mathrm{w} / \mathrm{v})$ for $4 \mathrm{~h}$. Anthers were then rinsed three times (15 min, each) with the buffer, dehydrated in the alcohol series, transferred to propylene oxide, and embedded in Epon epoxy resin. Semithin sections $(2.5 \mu \mathrm{m})$ prepared by an ultramicrotome were collected on glass slides and the periodic acid-Schiff (PAS) polysaccharide-specific reaction was carried out (Clément et al., 1994). PAS-positive reaction shows red color. Sections for staining were first plunged in $1 \%$ periodic acid $(\mathrm{w} / \mathrm{v})$ for $30 \mathrm{~min}$, then in Schiffs reagent for $20 \mathrm{~min}$, and finally in $5 \%$ sodium bisulfite $(\mathrm{w} / \mathrm{v})$ for $20 \mathrm{~min}$. Sections were then rinsed in distilled water, dried on a warm plate, and mounted in Histomount. Negative control was performed by omitting the oxidation step with periodic acid, and observed with a light microscope (Axioscop 2; Carl Zeiss, Oberkochen, Germany). For TEM investigations, ultrathin sections $(90 \mathrm{~nm})$ were collected on nickel grids, stained with uranyl acetate/lead citrate and examined on a TEM (LEO 906E; Carl Zeiss) at $100 \mathrm{kV}$.

SEM. To examine the morphological characters, anthers were fixed and dehydrated as described above, transferred to isoamyl acetate, and dried in an critical-point dryer (HCP-2; Hitachi, Tokyo, Japan) with carbon dioxide as the intermediate fluid. Samples were then coated with gold-palladium for $1 \mathrm{~min}$

Table 1. Flow cytometric analysis and fertility of the investigated Lilium lancifolium pollen grains.

\begin{tabular}{|c|c|c|c|}
\hline Ploidy level & $\begin{array}{c}\text { Relative DNA } \\
\text { contents per } \\
\text { nucleus }(1 \mathrm{C}=50.43)^{\mathrm{z}}\end{array}$ & $\begin{array}{c}\text { Pollen FDA } \\
\text { reaction }^{\mathrm{y}}\end{array}$ & $\begin{array}{c}\text { Pollen } \\
\text { germination } \\
(\%) \\
\end{array}$ \\
\hline $2 n=2 x=24$ & 38.4 & Bright green & 62.4 \\
\hline $2 n=3 x=36$ & 62.7 & No reaction & 0 \\
\hline
\end{tabular}

${ }^{\mathrm{z}}$ Mean of each 30 investigated plants; $1 \mathrm{C}=$ control DNA content.

${ }^{\mathrm{y}} \mathrm{FDA}=$ fluorescein diacetate, bright green $=$ viable pollen, no reaction $=$ nonviable. 
$30 \mathrm{~s}(10 \mu \mathrm{m})$ using an ion sputter (K 550; EMITECH, Chaswsieux, France) and examined on an SEM (2460-N; Hitachi) operating at an accelerating voltage of $15 \mathrm{kV}$. Pollen terminology was used according to Punt et al. (2007). Measurements were recorded as an average of 100 randomly sampled pollen grains for each specimen.

\section{Results}

In the diploid L. lancifolium, the stages of pollen development were identical to those reported by Nakamura (1979) and Clément et al. (1996). The development of each anther within a bud was asynchronous. It seemed that pollen development in diploid and triploid plants followed a similar phenotypic expression sequence of development events, but difference in tetrad formation was the starting point for the differentiation of pollen as fertile or sterile. It is noteworthy that although triploid pollen showed abnormal features compared with diploid pollen, the ontogeny was not interrupted but lasted until the dispersal.

\section{Development of fertile anther}

Microsporegenesis. During meiosis, the pollen mother cells were distinguished by their shape from the tapetal cells, which were devoid of starch grains, whereas their vacuoles were filled with a PAS-positive substance. Numerous starch grains were observed in staminal envelopes, and starch grains in the endothecium cells were larger than those in other middle layers and in the epidermis of anthers (data not shown). In the tetrad stage (Figs. 1C and 2A), the arrangement of microspores in a tetrad was isobilateral type (Mondal, 2015). There were microspores surrounded by the callose wall, tapetum vacuoles exhibited a PAS-positive reaction, and tapetal wall underwent degeneration. However, the tapetum tangential wall was still well defined. There was no change in the staminal envelopes. During the young microspore stage (Fig. 2C), the callose wall was entirely hydrolyzed and young microspores were released into the locular fluid and then showed heartshaped shells. The tapetal cells were polarized, and most of their cytoplasm was located on the locular side. Starch grains were not present in the microspores and staminal layers. In the microspore vacuolation stage (Fig. 2E), the microspores and staminal envelopes showed significant modifications at this time. The microspore swelled by vacuolation, and tapetal cells were still attached to each other and filled with lipids and residual products. Starch grains decreased in staminal envelopes compared with the former stage. During the premitosis stage (Fig. 2G), the microspore vacuole swelled, occupying almost the entire cellular volume, whereas starch grains were detected only in the stroma. Wall structures of the tapetum disintegrated, the tapetum almost degenerated, and lipids merged into the degenerating cytoplasm along the innermost middle layers. Pollenkitt released from the degenerating tapetum spread into the loculus.

Microgametogenesis. During the young bicellular pollen grain stage (Fig. 3A), the generative cell adhered to the young bicellular pollen grain wall and lacked starch. In the vegetative cell, the vacuole disappeared and starch grains reached its peak, observed overall, but lipid bodies were observed sporadically. The middle layers exhibited a PAS-positive reaction. The tapetum degenerated entirely and lipid globules attached to the middle layers of the tangential wall. The only stroma among the staminal envelopes contained starch grains. Lipids and residual products lay around in locular fluid. Pollenkitt was above the pollen grain exine. Lipid globules still clustered together in the innermost middle layers. During the generative cell-migration stage (Fig. 3C), the generative cell moved for center of the microgametophyte, and starch grains decreased in number/size compared with the prior phase. The staminal envelopes underwent amylogenesis, showing starch grains in the endothecium and middle layers. During the pollen grain maturation stage (Fig. $3 \mathrm{E})$, the elongated generative cell flattened in the middle of the pollen grain. In the cytoplasm of the vegetative cell, concurrent with lipid accumulation, starch grains were further decreased in size/number compared with the prior phase. The middle layers degenerated, while the endothecium wall remained thick. Finally, just before the anthesis stage (Fig. 3G), the pollen grain was almost entirely devoid of starch followed by the amylolytic state. When lipids filled the entire vegetative cell, the degenerated middle layers were arranged against the endothecial cell walls.
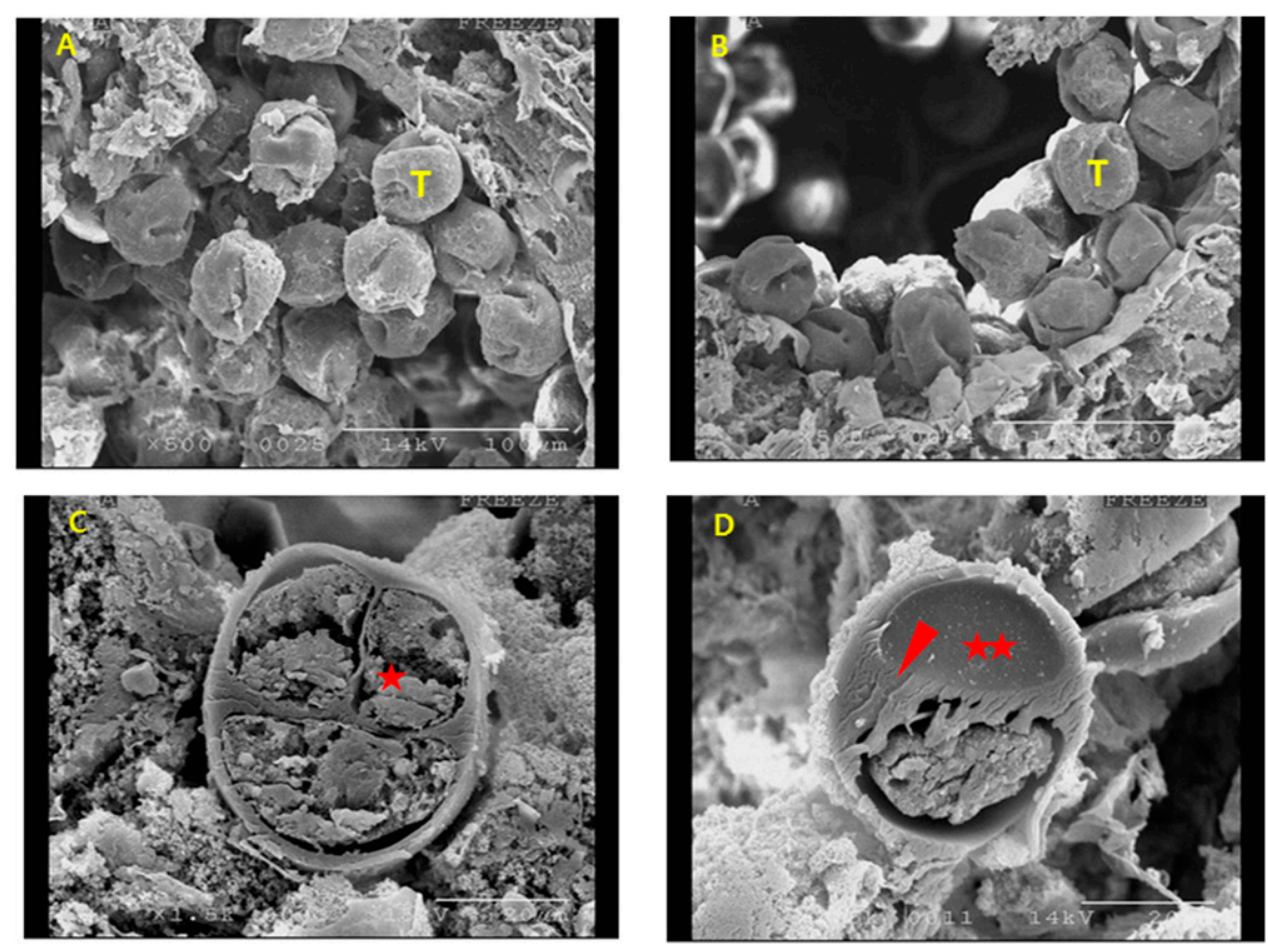

Fig. 1. Scanning electron microscopy of the tetrad of male fertile plants (left) and male sterile plants (right) at the tetrad stage of Lilium lancifolium. The external feature is analogous between (A) and (B), but, internally, (C) and (D) are very different: (C) normal tetrad (star), and (D) abnormal tetrad with a relatively thicker callose wall (arrowhead) and microsporic framework (double star marks); $\mathrm{T}=$ tetrad microspore; scale bars: $\mathbf{A}, \mathbf{B}=100 \mu \mathrm{m}$; C, $\mathbf{D}=20 \mu \mathrm{m}$ 

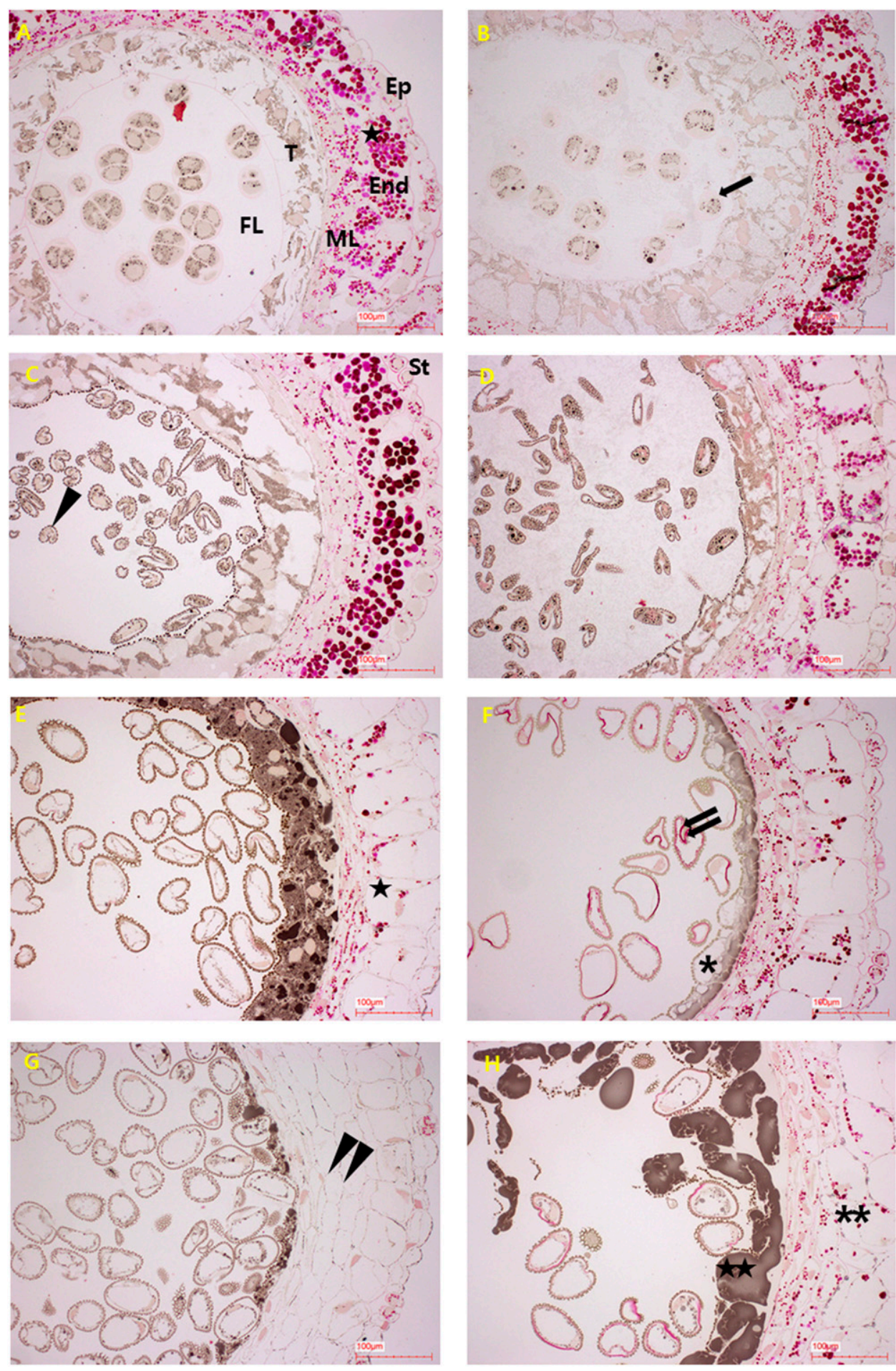

Fig. 2. Light microscopy of microsporogenesis in anthers of male fertile plants (left) and male sterile plants (right) of Lilium lancifolium. Cross sections of developing anthers were stained with periodic acid-Schiff (PAS) to localize polysaccharides: (A and $\mathbf{B})$ tetrad stage, $(\mathbf{C}$ and $\mathbf{D})$ young microspore stage, $(\mathbf{E}$ and $\mathbf{F})$ vacuolated microspore stage, and ( $\mathbf{G}$ and $\mathbf{H})$ premitosis stage. (A) Normal tetrad formation. (B) Abnormal tetrad formation; tetrads of haploid microspores were not definitively observed (arrow). (C) Young microspores showing a folding aperture that looks like heart-shaped shells (arrowhead). (D) The released microspores appear variable and shrunken. (E) Developing microspores show increasing cytoplasm, and the tapetum accumulates lipids. In addition, starch grains degrade in the anther walls (star mark). (F) Tapetal cells show abnormal vacuolation (asterisk), and the intine at the aperture region is PAS positive (double arrows). (G) The developing microspores contain round-shaped cytoplasm. Amylolysis occurs in the staminal envelopes (double arrowhead). (H) Excessive pollenkitt release into the loculus fluid (double star marks), and starch grains exit into the staminal envelopes (double asterisks); Ep $=$ epidermis, End $=$ endothecium, $\mathrm{ML}=$ middle layers, $\mathrm{T}=$ tapetum, $\mathrm{LF}=$ loculus fluid, $\mathrm{St}=$ stroma; scale bars $=100 \mu \mathrm{m}$.

\section{Development of sterile anther}

Microsporegenesis. During the meiosis stage, the triploid anther cells and pollen mother cells were identical to diploid (data not shown). However, in the tetrad stage (Fig. 2B), unlike the external morphology, the internal structure of the triploid pollen grain was quite distinct from that of the diploid pollen grain. The tetrad formation was defective, and each microspore in the tetrad had abnormal, poorly defined cytoplasm and was covered by a separate callose wall that was thicker than that of the diploid pollen grain (Fig. 1B and D). The tapetum cells showed a PASpositive reaction and had no signs of degeneration. The staminal envelopes were filled with starch grains. In the young microspore stage (Fig. 2D), released microspores were variable in size and shrunken. Degeneration of the tapetal cells, which lacked starch grains but showed a PASpositive reaction, was about to begin. Starch grains degraded in the endothecium during the prior stage. During the microspore vacuolation stage (Fig. 2F), vacuolated microspore was still shrunken and showed a few starch grains and conspicuously PAS-positive intine. Degeneration and abnormal vacuolation of the tapetum cells continued, whereas the staminal envelopes did not undergo any changes. In the premitosis (Fig. 2H), the vegetative cell was vacuolated and, unlike the premitosis in the diploid plant, staminal envelopes still contained starch grains. The tapetum cells dissolved and the space was occupied by huge lipid bodies, which grew further in size compared with the preceding stage. The intine was evident in the aperture area. These findings differed from those in the diploid plant.

Microgametogenesis. During the young bicellular pollen grain stage (Fig. 3B), the generative cell rarely adhered to the young bicellular pollen grain wall. In the vegetative cell, the vacuole disappeared and starch grains were observed irregularly, and substances such as lipid bodies occupied most of the abnormal cytoplasm. The cytoplasm had less starch grains and more lipids than the pollen grain of the diploid plant. Lipid bodies were released from the degenerated tapetum into 

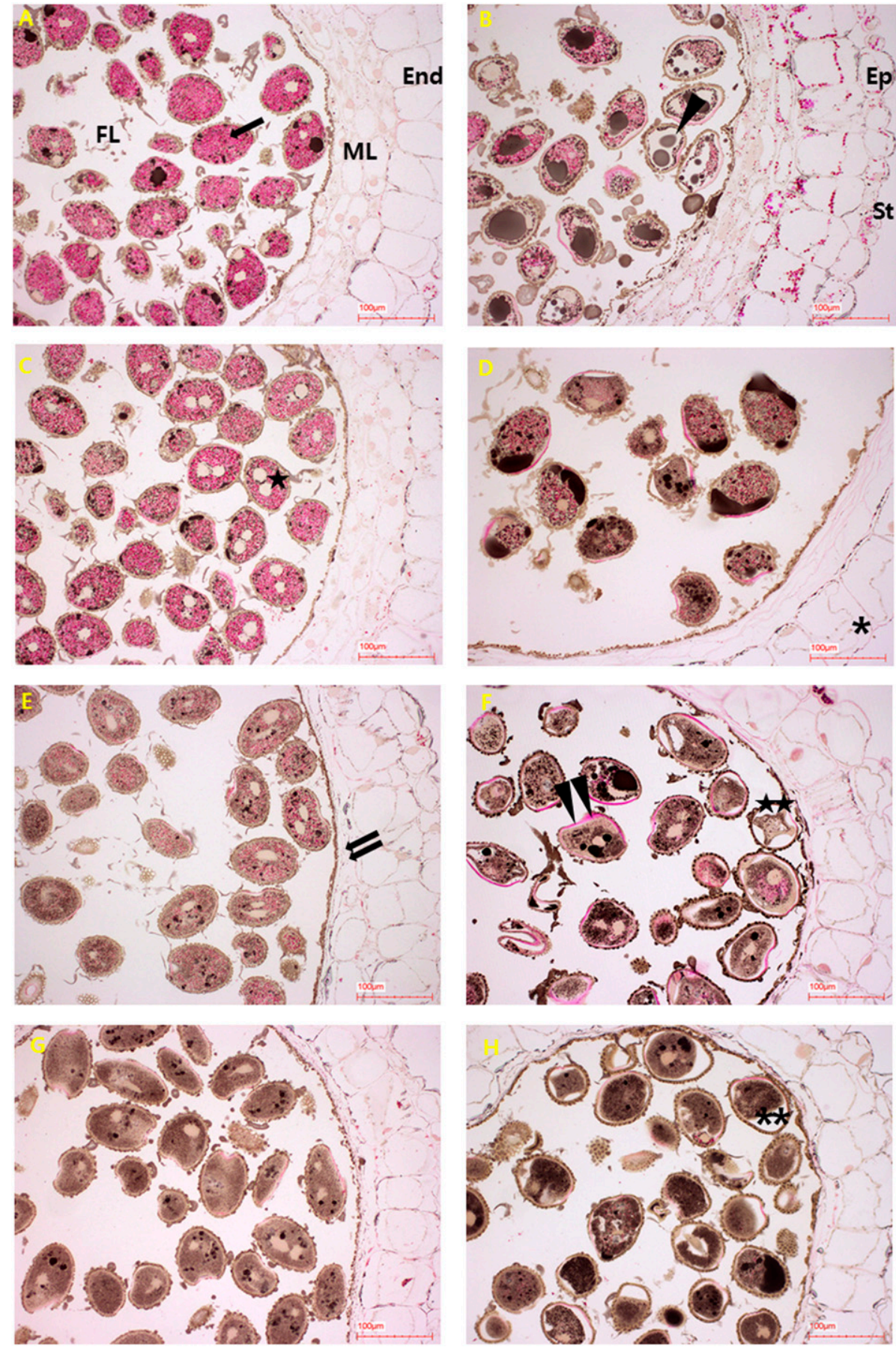

Fig. 3. Light microscopy of microgametogenesis in the anthers of male-fertile plants (left) and male-sterile plants (right) of Lilium lancifolium. Cross sections of the developing anthers were stained with PAS to localize polysaccharides. (A and B) The young bicellular pollen grain stage, (C and $\mathbf{D})$ the generative cell migration stage, $(\mathbf{E}$ and $\mathbf{F})$ the pollen grain maturation stage, and $(\mathbf{G}$ and $\mathbf{H})$ just before the anthesis stage. (A) The vegetative cells are engorged with PAS-positive starch grains (arrow). (B) The vegetative cells have abnormal cytoplasm that is empty or that contains a putative big lipid body (arrowhead). There are pollenkitt remains and lipid bodies in the loculus fluid. The starch distribution in the staminal envelopes remains unchanged. (C) The generative cell moves forward to the center of the pollen (star mark), and the starch grains degrade a little. (D) Maturing pollen bulks up and lipids occupy most of the cytoplasm. Amylolysis finally occurs in the anther walls (asterisk), and the middle layers begin to degenerate. (E) The generative cell is flattened in the center of the microgametophyte. PAS-positive starch grains are replaced by a large amount of lipids. The middle layers degenerate (double arrows) and are pressed flat against the thickened endothecium. (F) At the staminal envelopes, the events proceed like those in a diploid plant. However, at the pollen, the overexpressed PAS-positive intine (double arrowheads), excessive pollenkitt accumulation, and cytoplasm plasmolysis differ from a diploid plant (double star marks). (G) The starch grains completely disappear in the vegetative cell. $(\mathbf{H})$ The pollen surface volume seems not to decrease, but plasmolysis occurs. The cytoplasm grows less in the vegetative cells (double asterisks); Ep = epidermis, End = endothecium, $\mathrm{ML}=$ middle layers, $\mathrm{LF}=$ loculus fluid, $\mathrm{St}=$ stroma; scale bars $=100 \mu \mathrm{m}$. the locular fluid, and the staminal envelopes, unlike the diploid plantin the amylolytic state, had starch grains. In the generative cell migration stage (Fig. 3D), the cytoplasm of the vegetative cell was mottled with stains, starch grains and lipids halved quantitatively, and plasmolysis occurred. The amount of lipids was still higher than that in the diploid pollen grain. The middle layers degenerated, staminal envelopes lacked starch grains, but endothecium showed a PAS-positive reaction. In the pollen grain maturation stage (Fig. 3F), in the staminal envelopes, starch grains almost disappeared, and the envelopes showed a PASpositive reaction. The middle layers were pressed against the endothecium wall and contained lipid globules on the side facing the loculus. The intine of the aperture area was still visibly stained. Pollenkitt accumulated on the pollen exine in higher amounts than on the diploid pollen grain (Fig. 4B). Finally, just before the anthesis stage (Fig. $3 \mathrm{H}$ ), in the vegetative cell, the cytoplasm deepened plasmolysis (Fig. 5B) resulted in natural decline, starch grains disappeared, but lipids covered all. The staminal envelopes lacked starch grains and excessive amount of pollenkitt was observed covering the exine.

\section{Pollen morphology}

Numerical descriptions of the investigated pollen grains are summarized in Table 2. Representative pollen grain features are shown in Figs. 6 and 7. Both diploid and triploid pollen grains were dispersed as monads, their aperture form was monosulcate, and the exine ornamentation was reticulate.

Diploid POLLEN MORPHOLOGY. Pollen grains of the diploid L. lancifolium were released as monads, infolding; they were large in size $\{$ mean \pm SE [polar axis $(p)=126.4 \pm$ $8.4 \mu \mathrm{m}$, equatorial axis $(e)=49.0 \pm$ $2.9 \mu \mathrm{m}]\}$, isopolar, anatreme, with narrow, very deep apertures with rounded ends, spanning almost the equatorial diameter. The shape of the pollen grain was perprolate in equatorial view $(p / e=2.6)$, exine sculpture pattern was reticulate with muri formed by separated rectangular and rounded columellae $(2.0 \pm 0.3 \mu \mathrm{m})$, 

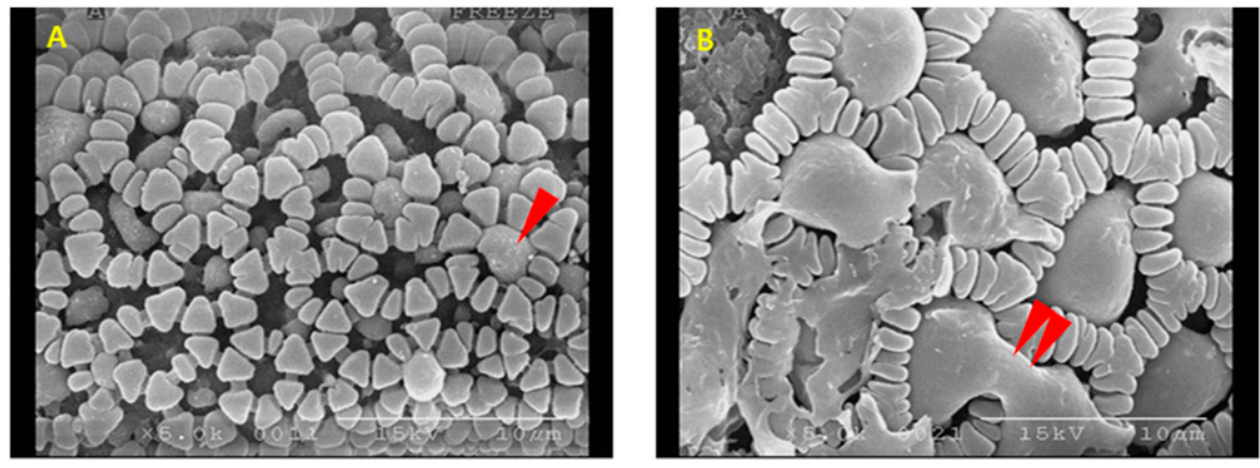

Fig. 4. Scanning electron microscopy of the pollen grain surface of male-fertile plants (left) and male-sterile plants (right) at the pollen maturation stage of Lilium lancifolium. (A) Pollenkitt droplets are deposited in the exine cavities (arrowhead). (B) Excess pollenkitt accumulates on the muri (double arrowheads); scale bars $=10 \mu \mathrm{m}$.
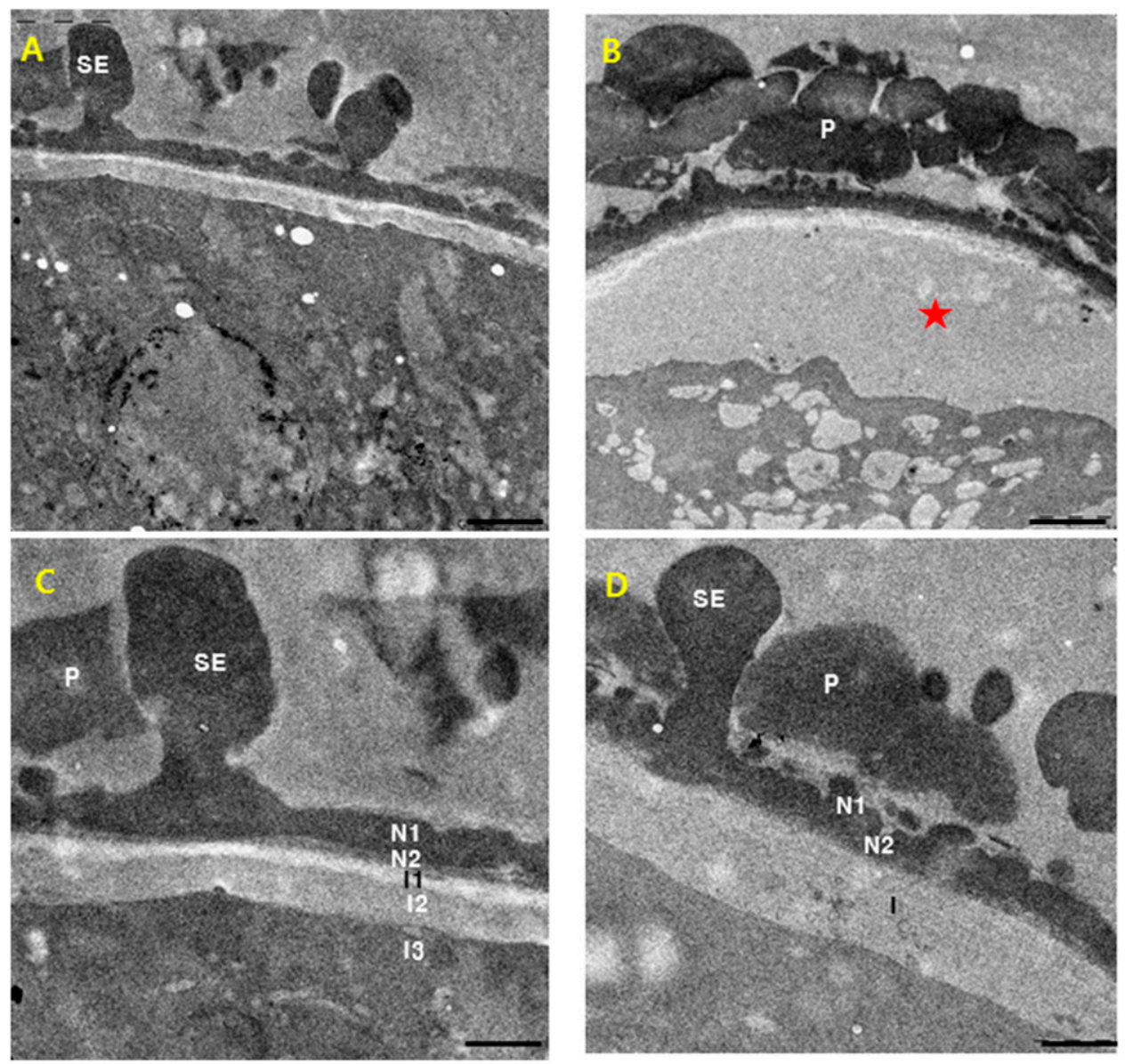

Fig. 5. Transmission electron microscopy of the pollen wall of male-fertile plants (left) and male-sterile plants (right) at the anthesis stage of Lilium lancifolium. (A) Mature pollen wall is normal. (B) During pollen maturation, plasmolysis occurring and the plasma membrane of the pollen grain withdrawn from the cell wall (star mark). (C) The stratification of the mature pollen wall consists of six layers. (D) Three layers of the triploid pollen wall intine are thicker and undifferentiated compared with that of the diploid pollen wall; $\mathrm{SE}=$ sexine, N1 $=$ nexine $1, \mathrm{~N} 2=$ nexine $2, \mathrm{I}=$ intine, $\mathrm{I} 1$ = intine $1 \mathrm{I} 2$ = intine $2, \mathrm{I} 3=$ intine $3, \mathrm{P}=$ pollenkitt; scale bars: $\mathbf{A}, \mathbf{B}=$ $2 \mu \mathrm{m}, \mathbf{C}, \mathbf{D}=1 \mu \mathrm{m}$.

discontinuous from the exposed tectum and wide lumina $(28.6 \pm$ $15.0 \mu \mathrm{m}^{2}$ area).

Triploid POLLen MORPhOLOGY. Triploid pollen were dispersed as monads, unfolding, appearing relatively larger in size $(p=105.5 \pm 9.0 \mu \mathrm{m}, e=61.3 \pm 5.7 \mu \mathrm{m})$ and inflated than diploid pollen, with a prolate form $(p / e=1.7)$. Muri were formed by separated rectangular columellae $(2.3 \pm 0.3 \mu \mathrm{m})$, continuous with a relatively wider caput and narrower lumina $\left(16.3 \pm 8.4 \mu \mathrm{m}^{2}\right.$ area $)$ than diploid.

\section{Discussion}

Tetrads Formation. The tetrad stage is a very important stage of pollen development and includes the following events: primexine formation, sporopollenin synthesis, tapetum degeneration, and development of pollen wall structure (Ariizumi and Toriyama, 2011; Jeong et al., 2014; Knox and Friederich, 1974; Noher et al., 1990; Owen and Makaroff, 1995).

Niizeki (1961) reported that in triploid pollen, in spite of the irregular distribution of chromosomes in the microspore cell nuclei, almost all the microspore cells separated just after the meiosis were morphologically normal and formed an outer exine with a characteristic relief pattern. The small cells, which were different from the normal tetrad cells, were often separated by an abnormal extra cytokinesis, and were also enveloped with an exine with a normal relief. Abnormal differentiation of the cytoplasm within the spore cells was observed even before the separation of the tetrad cells. The various abnormalities that may occur during the development of microspores to male gametophytes may result in irregular pollen grains (Niizeki, 1961). In concurrence, on our triploid microspore tetrad SEM images, while tetrad formation on the surface was normal, longitudinal and cross section showed microspore with abnormal cytoplasm. We are uncertain if the microspores that appeared superficially normal except the microspores filled with unknown materials were normal in actuality, or followed by normal developmental events.

Earlier research showed that the deformed pollen grains at the tetrad stage almost did not develop into mature pollen, i.e., they were aborted or degenerated (He et al., 1996; Huang, et al., 2009; Kim et al., 2013; Noher et al., 1990; Nuanjunkong et al., 2014). Despite being defective, the triploid microspore had been undergoing ontogeny followed by dispersal of a great deal of the sterile pollens. This means that pollen development must be programmed by the parental 
Table 2. Morphological characteristics of the investigated Lilium lancifolium pollen grains.

\begin{tabular}{|c|c|c|c|c|c|c|c|}
\hline \multirow[b]{3}{*}{ Ploidy level } & \multicolumn{2}{|c|}{ Pollen grain size $(\mu \mathrm{m})^{\mathrm{z}}$} & \multirow{3}{*}{$\begin{array}{c}p / e \\
\text { (ratio) }^{\mathrm{z}}\end{array}$} & & & \multirow{3}{*}{$\begin{array}{c}\text { Exine } \\
\text { structure }\end{array}$} & \multirow{3}{*}{$\begin{array}{c}\text { Pollen } \\
\text { type }\end{array}$} \\
\hline & $p$ & $e$ & & Muri $(\mu \mathrm{m})$ & Lumina $\left(\mu \mathrm{m}^{2}\right)$ & & \\
\hline & \multicolumn{2}{|c|}{$($ mean $\pm \mathrm{SE})$} & & \multicolumn{2}{|c|}{$($ mean $\pm \mathrm{SE})$} & & \\
\hline $2 n=2 x=24$ & $126.4 \pm 8.4$ & $49.0 \pm 2.9$ & 2.6 & $2.0 \pm 0.3$ & $28.6 \pm 15.0$ & Reticulate & Perprolate \\
\hline
\end{tabular}

${ }^{\mathrm{z} p}=$ polar axis, $e=$ equatorial axis.

genome. It will be worthwhile to gain an understanding of how abnormal events of triploid pollen development differ from those of other sterile pollen types.

Amylogenesis and amylolysis during pollen DEVELOPMENT. As the source of energy required for the series of morphological and physiological changes that lead to maturity and releasing of pollens, starch and other related polysaccharides are considered important in anthers and pollen grains growth, and their presence is correlated with one another (Castro and Clément, 2007; Clément et al., 1994, 1996; Noher et al., 1992; Pacini and Franchi, 1988; Pressman et al., 2002; Santos and Araujo, 1999). Diploid and triploid pollen grains went through cycles of amylogenesis-amylolosis during pollen ontogeny, similar to the pollen grains of other angiosperms (Bhadula and Sawhney, 1989; Pacini and Viegi, 1995). Diploid pollen grains showed a similar pattern to that observed in other pollen grains, but triploid pollen grains showed a different pattern. First, at the microspore premitosis stage, diploid pollen grains were in an amylolysis cycle and the starch disappeared in the staminal envelopes, whereas starch grains remained in the triploid pollen grains. At this stage, the microspore growth is determined by vacuolization (Clément et al., 1994, 1996; Pacini and Viegi, 1995; Yamamoto et al., 2003) followed by the formation of a new cytoplasm and pollen wall structures such as exine and intine layers. All the polysaccharides stored or consumed in the pollen grains are derived from the sporophyte, cross the tapetum, and level off at intine formation (Pacini and Viegi, 1995). The starch degradation may be linked to pollen wall deposition (polysaccharide layers) (Santos and Araujo, 1999). Thus, in diploid pollen grains, the transformation of the starch within the staminal envelopes into free sugar led to its consumption and then degradation. Our results revealed the abnormal operation of this starch metabolism in triploid pollen grains, which interfered with the formation of a normal cytoplasm and pollen wall structures such as exine and intine layers. Secondly, from the bicellular pollen grain stage to early pollen grain maturation, in diploid pollen grains, starch grains are numerous and engorged in the cytoplasm of the vegetative cell. Finally, during maturation, amylolysis occurred before anthesis. In similar studies, the authors interpreted that starch was hydrolyzed and transferred to the cytoplasm or used in RNA synthesis needed at germination (Pacini and Viegi, 1995). Clément et al. (1994) reported that starch is replaced by lipids. We found fewer starch grains and more lipid bodies in triploid pollen grains than in diploid. Many possibilities could explain this observation: 1) the mobilization of the staminal envelopes or loculus reserves such as polysaccharides may not be occurring effectively, it is possible that reserves from the staminal envelopes or loculus were not conveyed to the triploid pollen grains; 2) because of a cytoplasmic metabolism disorder in triploid pollen grains, the transferred polysaccharides may not be consumed, which could be followed by further lipid transformation; 3) it is possible that during polysaccharide transfer, these may be used in manufacturing other metabolites such as pollenkitt of high energy content (Pacini and Viegi, 1995). An interdependence in the production of such reserves during anther ontogeny have already been reported (Pacini and Viegi, 1995).

Despite this confusion in the cause and effect relationship, it is obvious that there is a disorder in triploid pollen ontogeny and polysaccharide metabolism followed by pollen aberration (Bhadula and Sawhney, 1989). This conclusion is supported by reports showing that stress-induced arrest of male-gametophyte development is preceded by disturbances in carbohydrate metabolism (Pressman et al., 2002). Furthermore, the polysaccharide distribution within anthers and the polysaccharide content of vegetative cells have been assumed to play a role in compatible and incompatible pollination in Oenothera organensis (Noher et al., 1992).

Pollen unfolding AND Plasmolysis. The morphological differences between triploid and diploid mature pollen grains were both external and internal. Externally they differed in the aperture folding and internally in the plasmolysis of the cytoplasm, which affected the pollen morphology. Observation of the triploid L. lancifolium in China was different from our result (Du et al., 2014), which can be explained in the reports that the characteristics of the triploid pollen morphology are structural varieties (Castro et al., 2013; Guo et al., 2010; Karlsdóttir et al., 2008).

Pollen apertures are an area generally characterized by a thinning of the external wall layer (exine) and a thickening of the internal wall layer (intine) (Albert et al., 2010). They perform several important functions in securing pollination success, and prevent pollen-wall breakage by permitting water loss (dehydration) and water uptake (rehydration) on the stigma (Albert et al., 2010; Firon et al., 2012). To survive this process, pollen wall generates surface-area-to-volume ratios that minimize water loss, which is called harmomegathy (Chaffey, 2010; Katifori et al., 2010). During harmomegathy, the pollen surface undergoes a folding process to produce a sealed pollen grain in which those permeable apertures become neatly tucked inside the impermeable exine (Chaffey, 2010; Couturier et al., 2013). Despite the early recognition of the importance of the pollen-wall structure in folding, the process remains obscure (Katifori et al., 2010). Just before anthesis, both diploid and triploid pollen grains are unfolded; however, after anthesis, the former are folded and the latter are unfolded. Pollen apertures are formed by intine that forms compliants that provide preferred sites of invagination that guide the folding (Katifori et al., 2010). Therefore, the unfolding of triploid pollen grains implicates a problem with intine structure.

In Arabidopsis thaliana, the plasma membrane was often withdrawn from the cell wall in amiR-atpv $42 b-1$ pollen grains that induced intine development delay. This is an indication of plasmolysis, implying that the abnormal cellular osmotic homeostasis inside the amiR-atpv $42 b-1$ pollen grains reduced the cell contents, followed by pollen abortion (Fang et al., 

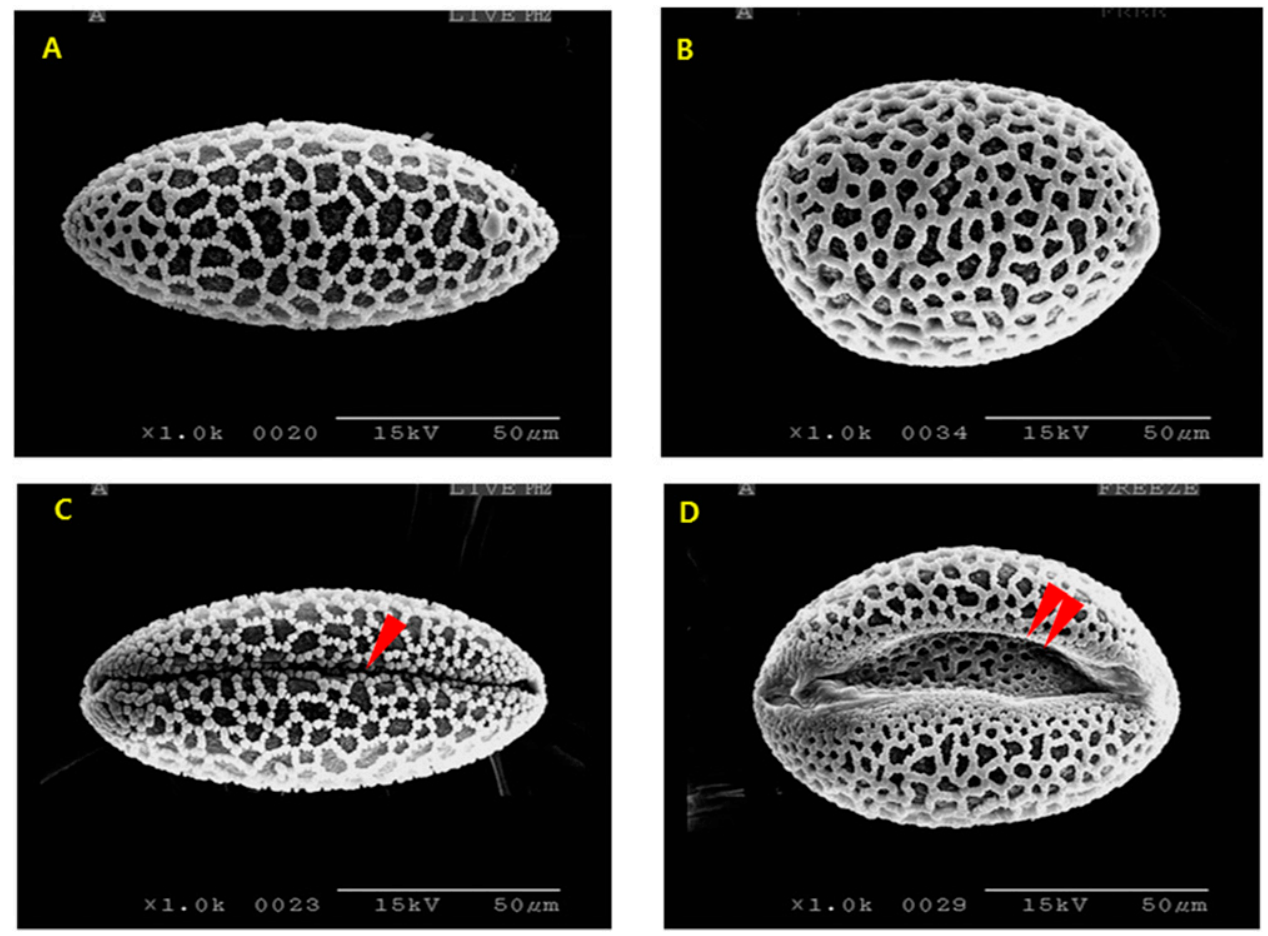

Fig. 6. Scanning electron microscopy image of a distal view of a pollen grain in male-fertile plants (left) and male-sterile plants (right) at the anther dehiscence of Lilium lancifolium. (A and B) The shape of the pollen grain is perprolate and prolate in the equatorial view, respectively. The pollen aperture pattern of two plants is monosulcate with a distal view. (C) Folding aperture - centered (arrowhead). (D) Unfolding aperture (double arrowheads); scale bars $=50 \mu \mathrm{m}$.
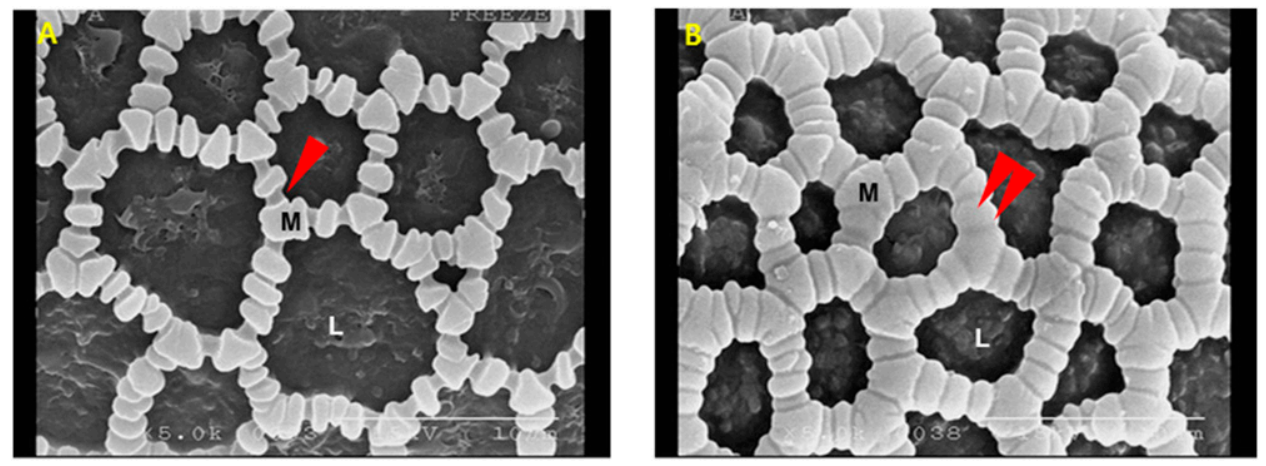

Fig. 7. Scanning electron microscopy of the exine ornamentation of male-fertile plants (left) and male-sterile plants (right) at the anthesis stage of Lilium lancifolium. (A) The muri are discontinuous from the exposed tectum (arrowhead), whereas (B) The muri are continuous with a relatively wide caput (double arrowheads); $\mathrm{M}=$ muri, $\mathrm{L}=$ lumina; scale bars $=10 \mu \mathrm{m}$.

2011). Similarly, in ms 1 mutants, minimal intine formation resulted in cytoplasm reduction and pollen grain degeneration (Vizcay Barrena and Wilson, 2006). The uneven distribution of the aperture and abnormal thickening of the intine observed in bcmf 2 transgenic plants followed by deformities in the transgenic mature pollens (Huang et al., 2009). The similarities between our results from observing triploid pollen grains and reports mentioned above support that our result also indicates the relationship between abnormalities in intine development and plasmolysis.

The intine is a cellulosic product of the microspore and includes several enzymes essential for compatibility reactions during germination, pollen-tube nutrition, and penetration of the stigma (Shoup et al., 1981; Vithanage and Knox, 1979). The intine is formed immediately after differentiation of the endexine, as the inner endexine is transformed into intine (Hess, 1993; Vizcay Barrena and Wilson, 2006). In Lilium species, the intine is subdivided into three layers, intine1, intine2, and intine3 (Nakamura, 1979), and its structure is considered an accommodation to pollen harmomegathy and pollen-tube growth during germination (Vega Maray et al., 2003). Intine differentiation is under gametophytic control, which in the lily is initiated during the tetrad stage (Vizcay Barrena and Wilson, 2006). The intine 1 is formed with material from the residuum of the primexine, and Golgi vesicles. The intine 2 originates from endoplasmic reticulum and near the aperture is very thick (Nakamura, 1979). The intine 2 of Parietaria judaica shows great elasticity and plasticity, which is probably due to the presence of pectin, which facilitates the intine 2 invaginations. These changes seem to involve the rough endoplasmic reticulum (RER) (Vega Maray et al., 2003). In our present study, unfolding and plasmolysis occurred even though triploid pollen grain wall showed more intensive PASpositive reaction than diploid pollen wall after vacuolated. We attributed this intense PAS-positive reaction to overdevelopment of cellulosic intine 1 , and suspected that deformation in structure of intine 2 caused the unfolding. Since it was difficult to observe pectinic intine 2 through PAS staining, we have observed the pollen grains with TEM technique. TEM images showed that unlike diploid pollen grains in which three sexine and three intine layers have developed evenly along pollen wall, only three layers of sexine have developed evenly in triploid pollens, and their intine layers were irregularly distributed with some layers difficult to separate clearly in several sites. To confirm the abnormality of triploid pollen grains, we attempted to compare our observation with intine development of another Lilium species, L. longiflorum, through earlier report by Nakamura (1979). However, we found that intine development of L. longiflorum differed from that of both diploid and triploid L. lancifolium, warranting further research such a cytochemical investigation. These tentative conclusions await further refinement and correction in the light of further research. Therefore, we cautiously propose that sterile triploid pollen relate with the intine layers malformation and the endoplasmic reticulum metabolism disorder. In male sterile plants, the carbohydrate 
depletion in the collapsed cytoplasm correlates with anomalies in pollen structure, so that anomalies in the intine structure may depend on the change in carbohydrate levels during pollen maturation (Pressman et al., 2002). In triploid pollen grains, after the abnormal tetrad stage, few starch reserves were observed in the matured pollen grains. Thus, triploid pollen grains show many characteristics capable of causing abnormal intine formation.

Pollenkitt distribution. Pollenkitt is commonly known to be the cause of allergic responses (Diego-Taboada et al., 2014) although its composition seems unlikely to be the same in all species, it is a hydrophobic mixture (Pacini and Hesse, 2005). In the Lilium species, it is mainly composed of a lipid component and carotenoid pigments that are produced in the tapetum (Heslop Harrison, 1968) and deposited on the pollen wall or in its sculptured cavities when the tapetum degenerates through the process of programmed cell death (PCD). The molecular signal of PCD most likely commences at the tetrad stage (Ariizumi and Toriyama, 2011; Jeong et al., 2014; Pacini and Viegi, 1995; Rosenfeldt and Galati, 2005). Pollenkitt plays a role in the protection of pollen cells from excessive desiccation after dehiscence, ultraviolet radiation, pathogen attack, and interactions with pollinators. Furthermore, it contains protein components involved in adhesion, signaling, and compatibility, as well as lipids for rehydration (Ariizumi and Toriyama, 2011). Interestingly, pollenkitt starts to play its roles as soon as anthers open, continues during pollen exposure and dispersal, and presumably ceases when pollen grains rehydrate on the stigma (Pacini and Hesse, 2005). Thus, it plays a major role in the exposure of pollen grains to the exterior environment.

During pollen development, significant differences between diploid and triploid pollen grains were found in the pollenkitt distribution in the loculus. Both plants showed pro-orbicles at the microspore release stage, increased lipid bodies in the tapetum and, then, pollenkitt after the tapetum degenerated. However, after microspore vacuolation, the degenerated tapetum was displaced by excessive pollenkitt in triploid pollen grains, compared with that in diploid pollen grains. The excess pollenkitt was released into the loculus followed by its accumulation on the pollen exine or cavity. A great amount of pollenkitt prevents the folding of pollen with thin walls, as in some Passifloraceae species (Pacini and Hesse, 2005). This is in agreement with our results, where triploid pollen grains failed to fold their apertures during harmomegathy.

What induced excessive pollenkitt accumulation in triploid pollen grains? The ultrastructural changes observed during the different stages of tapetal cell development are related to Ubisch bodies (orbicules), sporopollenin, and pollenkitt formation (Owen and Makaroff, 1995; Rosenfeldt and Galati, 2005). Orbicules are minute sporopollenin bodies in the anther loculus (Bhandari and Kishori, 1971; D'Hondt et al., 2004). The parallelism between the pollen exine that consists of sporopollenin and the orbicule is explained by Hesse (1986) as rooted in the homology of tapetum and sporophytic tissue (Hesse, 1986; Owen and Makaroff, 1995). Once microspore exine is essentially complete and the tapetal cells have begun the production of materials that will coat the mature pollen grains (Owen and Makaroff, 1995), the proplastids of tapetal cells first differentiate into elaioplasts and then are replaced by roundish lipidic masses that later form the pollenkitt (Chen et al., 1988), which is mainly a mixture of two components: elaioplasts and spherosomes. The former are the product of a distinct type of plastid with lipid reserves, the elaioplasts; the latter are the result of endoplasmic reticulum lipid accumulation (Pacini and Hesse, 2005). These materials accumulate in aborted pollen, too. Despite numerous studies, the functions of orbicules remain obscure (Gotelli et al., 2012; Wang et al., 2003). Because each body is in a homogeneous group, controversy is likely to continue over whether corelationship between their formation is positive or negative (Keijzer, 1987; Pacini and Franchi, 1993). In A. thaliana faceless pollen-1 male-sterile mutant showed that the smooth and less sculpturing reticulate pattern appearance of the pollen surface was due to excess tryphine (pollen coat) filling in the exine cavities, while sporopollenin was defective in the mutant (Ariizumi et al., 2003). Combined with our work, the aforementioned research reports pose interesting possibilities. Previous studies have reported that stress-induced male sterility is conferred by the combinatorial effect of multiple cellular defects that all originate from alterations in tapetal RER. Consequently, tapetal RER constitutes an important center of stress sensitivity and mediates stress-induced male sterility through a variety of biological processes (Lalonde et al., 1997; Storme and Geelen, 2014). Triploid pollen grains occurred because of the irregular distribution of chromosomes in the microspore cell resulting in an incomplete state, which could cause excessive stress in the plant. In turn, this could trigger a defense mechanism capable of inducing an excessive accumulation of sporopollenin and pollenkitt to protect the pollen grains. However, this excessive pollenkitt accumulation induced the unfolding aperture, which adversely affected pollen fertility. Consequently, this means that the pollenkitt released by the tapetum (sporophytic origin) must be programmed by the parental genome (Gabarayeva et al., 2009), but is influenced by the incomplete tetrad formation (gametophytic origin).

In addition, as contamination by pollen is relevant, recent research has considered the possibility of pollenless lily breeding (Yamagishi, 2003). On the contrary, triploid pollen with both sterility and extensive pollen coat is an attractive material; therefore, further research into its ontogeny mechanism may produce interesting results.

Pollen OUTER EXINe SCULPTURING. Pollen grains are typically covered by a chemically and physically resistant outer cell wall called the exine, which consists of durable sporopollenin (Ariizumi and Toriyama, 2011). The role of the exine is to provide structural and physical support to the microspore cytoplasm containing the sperm, and protection from harsh conditions against many stressors, as plants are unable to move (Edlund et al., 2004). The astonishing diversity in pollen morphology, which is related to pollinator attraction and to the first contact with the female stigma, is mostly associated with the sculptural structure of the exine. Exine pattern formation is most likely dependent on three developmental processes: synthesis of sporopollenin precursors, primexine formation, and callose wall formation (Ariizumi and Toriyama, 2011; Guan et al., 2008). However, the processes responsible for generating the characteristic pollen feature or spore wall structure, and exine patterning remain unknown (Gabarayeva et al., 2009). In the Lilium species, the formation of the exine begins at the tetrad stage (Nakamura, 1979), and it is obvious at the microspore release stage after the tetrad (Clément et al., 1994).

Both diploid and triploid pollen grains showed an exine at the microspore release stage, and a reticulate type like an exine sculpture pattern observed in other lilies. At the anthesis stage, triploid pollen grains showed an exine pattern less sculptured 
than that of diploid pollen grains. According to the description within the Lilium genus, based on the number, shape, and arrangement of the columellae that form the muri (Baranova, 1985), diploid pollen grain showed intergrade between Martagon (muri formed by rectangular columellae) type and Callose (muri formed by rounded columellae) type, whereas triploid pollen grain was classified as Martagon type. It is hypothesized that the evolution of an exine sculpture shows the following pollen-type trend: Martagon $\rightarrow$ Callose $\rightarrow$ Concolor $\rightarrow$ Formosanum (Du et al., 2014). The evolutionary trend regarding pollen sculpture and size could be related to the selective pressures to adapt to new environmental conditions. Therefore, the unique exine surface pattern has been credited with the taxonomic value ( $\mathrm{Du}$ et al., 2014; Muratović et al., 2010). The triploid pollen of Lilium species in China showed a different sculpture pattern from that of our triploid (Du et al., 2014). Anther development within the triploid is highly asynchronous and pollen morphology from triploid plants is variable (Castro and Clément, 2007; Karlsdóttir et al., 2008). Our results, rather than the outside environment and evolution, seems that sporopollenin produced at the tapetum (sporophytic origin) and accumulated on the primexine (gametophytic origin), sporopollenin receptor after the abnormal tetrad stage, in turn failed to sculpt exine pattern.

Similar consequences have been found in several male sterile mutants. In $A$. thaliana ms 1 mutants with altered tapetal PCD and pollen wall development (Dawson et al., 1993; Wilson et al., 2001), the mutant exine appears disorganized and translucent due to the poorly resolved vacuole (Vizcay Barrena and Wilson, 2006). TRANSPOSABLE ELEMENT SILENCING VIA AT-HOOK (TEK) mutant leads to male sterility caused by the absence of exine and intine layers (Lou et al., 2014). However, these genes are mostly expressed in the tapetum (sporophytic origin), and at pollen maturation, they result in the abortion and extinction of pollen grains, which is different from what observed from triploid pollens. We suspect that triploid occurs irregular distribution of chromosomes does not suppress the expression of genes but merely affect it resulting in male sterility under both sporophytic-origin tapetum and gametophytic-origin microspore control. In this comparative study of pollen development between fertile diploid and sterile triploid tiger lily plants, our results reveal an interesting correlation between fertility and pollen ontogeny. Especially, this corresponded with sporophytic and gametophytic original tissues and was different from male sterile gene mutant ontogeny. Our results denote that the pollen wall structure not only has a morphological function, but also influences the reproductive pathway and that natural polyploid plants appear to have more unpredictable consequences.

The unusual and interesting phenomena showed by our special materials propose the need for broad research on the diversity of morphological expression of natural male sterile polyploid such as L. lancifolium. For definite studies, we will perform subcellular level analysis by TEM and cytochemical reactions using the various dyes.

\section{Literature Cited}

Albert, B., S. Nadot, L. Dreyer, and A. Ressayre. 2010. The influence of tetrad shape and intersporal callose wall formation on pollen aperture pattern ontogeny in two eudicot species. Ann. Bot. (Lond.) 106(4):557-564.

Ariizumi, T., K. Hatakeyama, K. Hinata, S. Sato, T. Kato, S. Tabata, and K. Toriyama. 2003. A novel male-sterile mutant of Arabidopsis thaliana, faceless pollen-1, produces pollen with a smooth surface and an acetolysis-sensitive exine. Plant Mol. Biol. 53(1-2):107116.

Ariizumi, T. and K. Toriyama. 2011. Genetic regulation of sporopollenin synthesis and pollen exine development. Annu. Rev. Plant Biol. 62:437-460.

Baranova, M.V. 1985. Palynoderm ultrastructure and morphological types of pollen grains in the genus Lilium (Liliaceae). Botanichyeskii Zhurnal (Leningrad) 70:297-304.

Bhadula, S.K. and V.K. Sawhney. 1989. Amylolytic activity and carbohydrate levels during the stamen ontogeny of a male fertile, and a 'gibberellin-sensitive' male sterile mutant of tomato (Lycopersicon esculentum). J. Expt. Bot. 40(7):789-794.

Bhandari, N.N. and R. Kishori. 1971. Übisch granules on tapetal membranes in anthers: Rapid selective staining by spirit blue. Biotech. Histochem. 46:15-17.

Castro, A.J. and C. Clément. 2007. Sucrose and starch catabolism in the anther of Lilium during its development: A comparative study among the anther wall, locular fluid and microspore/pollen fractions. Planta 225(6):1573-1582.

Castro, A.J., E. Garcia, T.M. Caballero, L. Linares, C. Perez, A. Pinar, N. Rivas, N.V. Santillán, K. Zienkiewicz, A. Zienkiewicz, M. Jamilena, and J.D. Alché. 2013. Seedless watermelons: From the microscope to the table through the greenhouse. High School Students Agr. Sci. Res. Proc. 3rd Congress PIIISA:27-32.

Chaffey, N. 2010. Plant cuttings. Ann. Bot. (Lond.) 105(6):v-viii.

Chandler, C., W.M. Porterfield, and A.B. Stout. 1937. Microsporogenesis in diploid and triploid types of Lilium tigrinum with special references to abortions. Cytol. Fujii Jubilee 2:756-784.

Chen, Z.K., F.H. Wang, and F. Zhou. 1988. On the origin, development and ultrastructure of the orbicuies and pollenkitt in the tapetum of Anemarrhena asphodeloides (Liliaceae). Grana 27(4):273-282.

Clément, C., L. Chavant, M. Burrus, and J. Audran. 1994. Anther starch variations in Lilium during pollen development. Sex. Plant Reprod. 7(6):347-356.

Clément, C., M. Burrus, and J.-C. Audran. 1996. Floral organ growth and carbohydrate content during pollen development in Lilium. Amer. J. Bot. 83:459-469.

Couturier, E., J. Dumais, E. Cerda, and E. Katifori. 2013. Folding of an opened spherical shell. Soft Matter 9:8359-8367.

D'Hondt, C., P. Schols, S. Huysmans, and E. Smets. 2004. Systematic relevance of pollen and orbicule characters in the tribe Hillieae (Rubiaceae). Bot. J. Linn. Soc. 146(3):303-321.

Dawson, J., Z.A. Wilson, M.G.M. Aarts, A.F. Braithwaite, L.G. Briarty, and B.J. Mulligan. 1993. Microspore and pollen development in six male-sterile mutants of Arabidopsis thaliana. Can. J. Bot. 71(4):629-638.

De Jong, P.C. 1974. Some notes on the evolution of lilies, p. 23-28. In: J.F. McBae (ed.). The lily yearbook of the North American Lily Society. No. 27. North Amer. Lily Soc., New York, NY.

Diego-Taboada, A., S.T. Beckett, S.L. Atkin, and G. Mackenzie. 2014. Hollow pollen shells to enhance drug delivery. Pharmaceutics 6:80-96.

Du, Y.P., C. Wei, Z.X. Wang, S. Li, H.B. He, and G.X. Jia. 2014. Lilium spp. pollen in China (Liliaceae): Taxonomic and phylogenetic implications and pollen evolution related to environmental conditions. PLoS One 9(1):e87841.

Edlund, A.F., R. Swanson, and D. Preuss. 2004. Pollen and stigma structure and function: The role of diversity in pollination. Plant Cell 16:S84-S97. Erdtman, G. 1960. The acetolysis method. A revised description. Sven. Bot. Tidskr. 54:561-564.

Fang, L., X. Hou, L.Y.C. Lee, L. Liu, X. Yan, and H. Yu. 2011. AtPV42a and AtPV42b redundantly regulate reproductive development in Arabidopsis thaliana. PLoS One 6(4):e19033.

Firon, N., M. Nepi, and E. Pacini. 2012. Water status and associated processes mark critical stages in pollen development and functioning. Ann. Bot. (Lond.) 109(7):1201-1214. 
Gabarayeva, N., V. Grigorjeva, J.R. Rowley, and A.R. Hemsley. 2009. Sporoderm development in Trevesia burckii (Araliaceae): II. Posttetrad period: Further evidence for the participation of self-assembly processes. Rev. Palaeobot. Palynol. 156(1-2):233-247.

Gotelli, M., B. Galati, and D. Medan. 2012. Pollen, tapetum, and orbicule development in Colletia paradoxa and Discaria americana (Rhamnaceae). Sci. World J. 8:948469.

Guan, Y.-F., X.-Y. Huang, J. Zhu, J.-F. Gao, H.-X. Zhang, and Z.-N. Yang. 2008. RUPTURED POLLEN GRAIN1, a member of the $\mathrm{MtN} 3 /$ saliva gene family, is crucial for exine pattern formation and cell integrity of microspores in arabidopsis. Plant Physiol. 147(2): 852-863.

Guo, Q.G., Q. He, K. Ji, Q. Wu, C. Zhang, W.X. Wang, X.L. Li, and G. L. Liang. 2010. Analysis on the anther and pollen morphology of triploid loquat. Acta Hort. 887:265-270.

He, S., A.R. Abad, S.B. Gelvin, and S.A. Mackenzie. 1996. A cytoplasmic male sterility-associated mitochondrial protein causes pollen disruption in transgenic tobacco. Proc. Natl. Acad. Sci. USA 93(21):11763-11768.

Heslop Harrison, J. 1968. Tapetal origin of pollen-coat substances in Lilium. New Phytol. 67(4):779-786.

Hess, M.W. 1993. Cell-wall development in freeze-fixed pollen: Intine formation of Ledebouria socialis (Hyacinthaceae). Planta 189(1): 139-149.

Hesse, M. 1986. Orbicules and the ektexine are homologous sporopollenin concretions inSpermatophyta. Plant Syst. Evol. 153(1-2):37-48.

Huang, L., J. Cao, A. Zhang, Y. Ye, Y. Zhang, and T. Liu. 2009. The polygalacturonase gene BcMF2 from Brassica campestris is associated with intine development. J. Expt. Bot. 60(1):301-313.

Hwang, Y.J., H.H. Kim, J.B. Kim, and K.B. Lim. 2011. Karyotype analysis of Lilium tigrinum by FISH. Hort. Environ. Biotechnol. 52(3): 292-297.

Jeong, H., J.H. Kang, M. Zhao, J.K. Kwon, H.S. Choi, J.H. Bae, H.a. Lee, Y.H. Joung, D. Choi, and B.C. Kang. 2014. Tomato male sterile 1035 is essential for pollen development and meiosis in anthers. J. Expt. Bot. 65(22):6693-6709.

Karlsdóttir, L., M. Hallsdóttir, A.T. Thórsson, and K. AnamthawatJónsson. 2008. Characteristics of pollen from natural triploid Betula hybrids. Grana 47(1):52-59.

Katifori, E., S. Alben, E. Cerda, D.R. Nelson, and J. Dumais. 2010. Foldable structures and the natural design of pollen grains. Proc. Natl. Acad. Sci. USA 107(17):7635-7639.

Keijzer, C. 1987. The processes of anther dehiscence and pollen dispersal. II. The formation and the transfer mechanism of pollenkitt, cell-wall development of the loculus tissues and a function of orbicules in pollen dispersal. New Phytol. 105(3):499-507.

Kim, J.H., H.Y. Kyung, J.K. Lee, M. Hiramatsu, and H. Okubo. 2006. Geographic distribution and habitat differentiation in diploid and triploid L. lancifolium of South Korea. J. Faculty Agr. Kyushu Univ. 51:239-243.

Kim, Y., Y.E. Davaasuren, H.Y. Kyung, Y. Xuan, C.H. Kim, J.K. Lee, and Y.S. Choi. 2005. Morphological variation of fiploid and triploid of L. lancifolium in Korea. J. Korean Flower Res. Soc. 13:283-288.

Kim, Y.M., Y.D. Jo, J.-K. Kwon, I.T. Kim, and B.C. Kang. 2013. Characterization and inheritance of a novel thermo-sensitive restoration of cytoplasmic male sterility in Capsicum annuum. Sci. Hort. 164:512-520.

Knox, R.B. and E. Friederich. 1974. Tetrad pollen grain development and sterility in Leschenaultia formosa (Goodeniaceae). New Phytol. 73(1):251-258.

Lalonde, S., D.U. Beebe, and H. Saini. 1997. Early signs of disruption of wheat anther development associated with the induction of male sterility by meiotic-stage water deficit. Sex. Plant Reprod. 10(1):40-48.

Lou, Y., X.F. Xu, J. Zhu, J.N. Gu, S. Blackmore, and Z.N. Yang. 2014. The tapetal AHL family protein TEK determines nexine formation in the pollen wall. Nat. Commun. 5, doi: 10.1038/ncomms 4855 .
Moens, P.B. 1969. The fine structure of meiotic chromosome pairing in the triploid, Lilium tigrinum. J. Cell Biol. 40(1):273-279.

Mondal, P.Stamen: Male reproductive organ in flowering plants. 1 Feb. 2015. <http://www.yourarticlelibrary.com/biology/stamenmale-reproductive-organ-in-flowering-plants/11816/>.

Muratović, E., F. Bogunić, D. Šoljan, J. Martín, J. Vallès, and S. SiljakYakovlev. 2010. Stomata and pollen grain characteristics of two endemic lilies: Lilium bosniacum and L. carniolicum (Liliaceae). Phytol. Balcanica 16:285-292.

Nakamura, S. 1979. Development of the pollen grain wall in Lilium longiflorum. J. Electron Microsc. (Tokyo) 28(4):275-284.

Niizeki, S. 1961. Some considerations on the self-sterility in the triploid Lilium tigrinum. Ochanomizu Univ. Natural Sci. Rpt. 12(2):37-42.

Noda, S. 1978. Chromosomes of diploid and triploid forms found in the natural populations of tiger lily in Tsushima. Bot. Mag. 91(4): 279-283.

Noda, S. 1986. Cytogenetic behavior, chromosomal differentiations, and geographic distribution in Lilium lancifolium (Liliaceae). Plant Species Biol. 1(1):69-78.

Noher, D.H.I., I.A. Cismondi, and C. Harte. 1990. Pollen ontogenesis in Oenothera: A comparison of genotypically normal anthers with the male-sterile mutant sterilis. Sex. Plant Reprod. 3(1):41-53.

Noher, D.H.I., G. Fama, and I.A. Cismondi. 1992. Changes in lipids and polysaccharides during pollen ontogeny in Oenothera anthers. Sex. Plant Reprod. 5(2):110-116.

Nuanjunkong, N., C. Purintavaragul, and U. Meesawat. 2014. Abortive pollen development in relation to early tapetal degradation in male sterile mangosteen. Acta Hort. 1024:217-221.

Okazaki, K. 1994. Lilium species native to Japan, and breeding and production of Lilium in Japan. Acta Hort. 414:81-92.

Owen, H.A. and C. Makaroff. 1995. Ultrastructure of microsporogenesis and microgametogenesis in Arabidopsis thaliana (L.) Heynh. ecotype Wassilewskija (Brassicaceae). Protoplasma 185(1-2):7-21.

Pacini, E. and G. Franchi. 1988. Amylogenesis and amylolysis during pollen grain development, p. 181-186. In: M. Cresti, P. Gori, and E. Pacini (eds.). Sexual reproduction in higher plants. Springer, Berlin/Heidelberg, Germany.

Pacini, E. and G. Franchi. 1993. Role of the tapetum in pollen and spore dispersal. Plant Syst. Evol. 7(Suppl.):1-11.

Pacini, E. and L. Viegi. 1995. Total polysaccharide content of developing pollen in two angiosperm species. Grana 34(4):237-241.

Pacini, E. and M. Hesse. 2005. Pollenkitt-its composition, forms and functions. Flora 200(5):399-415.

Pressman, E., M.M. Peet, and D.M. Pharr. 2002. The effect of heat stress on tomato pollen characteristics is associated with changes in carbohydrate concentration in the developing anthers. Ann. Bot. (Lond.) 90(5):631-636.

Punt, W., P. Hoen, S. Blackmore, S. Nilsson, and A. Le Thomas. 2007. Glossary of pollen and spore terminology. Rev. Palaeobot. Palynol. 143(1-2):1-81.

Rhee, H.K., H.R. Cho, K.J. Kim, and K.S. Kim. 2005. Comparison of pollen morphology in interspecific hybrid lilies after in vitro chromosome doubling. Acta Hort. 673:639-643.

Rosenfeldt, S. and B.G. Galati. 2005. Ubisch bodies and pollen ontogeny in Oxalis articulata Savigny. Biocell 29(3):271-278.

Santos, R.P. and M.J.E.D. Araujo. 1999. Storage substances in the androgametogenesis and mature pollen grain of Ilex paraguariensis St. Hil. (Aquifoliaceae). Rev. Bras. Bot. Braz. J. Bot. 22(2):125-131.

Schaffner, J.H. 1906. Chromosome reduction in the microsporocytes of Lilium tigrinum. Bot. Gaz. 41(3):184-192.

Shoup, J.R., J. Overton, and M. Ruddat. 1981. Ultrastructure and development of the nexine and intine in the pollen wall of Silene alba (Caryophyllaceae). Amer. J. Bot. 68(8):1090-1095.

Stewart, R.N. and R. Bamford. 1943. The nature of polyploidy in Lilium tigrinum. Amer. J. Bot. 30(1):1-7.

Storme, N.D. and D. Geelen. 2014. The impact of environmental stress on male reproductive development in plants: Biological processes and molecular mechanisms. Plant Cell Environ. 37(1):1-18. 
Takenaka, Y. and T. Nagamatsu. 1930. On the chromosomes of Lilium tigrinum KER-GAWL. Bot. Mag. 44(523):386-391.

Vega Maray, A.M., D. Fernandez-Gonzalez, R. Valencia-Barrera, J.A. Seoane-Camba, and M. Suarez-Cervera. 2003. Ultrastructural modifications in the apertural intine of Parietaria judaica L. (Urticaceae) pollen during the early stages of hydration. Grana 42(4): 220-226.

Vithanage, H. and R.B. Knox. 1979. Pollen development and quantitative cytochemistry of exine and intine enzymes in sunflower, Helianthus annuus L. Ann. Bot. (Lond.) 44(1):95106.

Vizcay Barrena, G. and Z.A. Wilson. 2006. Altered tapetal PCD and pollen wall development in the arabidopsis ms 1 mutant. J. Expt. Bot. 57(11):2709-2717.
Wang, A., Q. Xia, W. Xie, R. Datla, and G. Selvaraj. 2003. The classical Ubisch bodies carry a sporophytically produced structural protein (RAFTIN) that is essential for pollen development. Proc. Natl. Acad. Sci. USA 100(24):14487-14492.

Wilson, Z.A., S.M. Morroll, J. Dawson, R. Swarup, and P.J. Tighe. 2001. The Arabidopsis MALE STERILITY1 (MS1) gene is a transcriptional regulator of male gametogenesis, with homology to the PHD-finger family of transcription factors. Plant J. 28 (1):27-39.

Yamagishi, M. 2003. A genetic model for a pollenless trait in Asiatic hybrid lily and its utilization for breeding. Sci. Hort. 98(3):293-297. Yamamoto, Y., M. Nishimura, I. Hara Nishimura, and T. Noguchi. 2003. Behavior of vacuoles during microspore and pollen development in Arabidopsis thaliana. Plant Cell Physiol. 44(11):1192-1201. 